\title{
Tricuspid annuloplasty prevents right ventricular dilatation and progression of tricuspid regurgitation in patients with tricuspid annular dilatation undergoing mitral valve repair
}

\author{
Nico R. Van de Veire, MD, PhD, ${ }^{a}$ Jerry Braun, MD, ${ }^{b}$ Victoria Delgado, MD, ${ }^{a}$ Michel I. M. Versteegh, MD, ${ }^{\mathrm{b}}$ \\ Robert A. Dion, MD, PhD, ${ }^{\mathrm{b}}$ Robert J. M. Klautz, MD, PhD, ${ }^{\mathrm{b}}$ and Jeroen J. Bax, MD, PhD ${ }^{\mathrm{a}}$
}

\begin{abstract}
Objectives: We hypothesize that concomitant tricuspid annuloplasty in patients with tricuspid annular dilatation who undergo mitral valve repair could prevent progression of tricuspid regurgitation and right ventricular remodeling.
\end{abstract}

\begin{abstract}
Methods: In 2002, 80 patients underwent mitral valve repair. Concomitant tricuspid annuloplasty was performed in 13 patients with grade 3 or 4 tricuspid regurgitation. In 2004, 102 patients underwent mitral valve repair. Concomitant tricuspid annuloplasty was performed in 21 patients with grade 3 or 4 tricuspid regurgitation and in 43 patients with an echocardiographically determined tricuspid annular diameter of $40 \mathrm{~mm}$ or greater. Patients underwent transthoracic echocardiographic analysis preoperatively and at the 2-year follow-up.
\end{abstract}

\begin{abstract}
Results: In the 2002 cohort right ventricular dimensions did not decrease (right ventricular long axis, $69 \pm 7$ vs $70 \pm 8 \mathrm{~mm}$; right ventricular short axis, $29 \pm 7$ vs $30 \pm 7 \mathrm{~mm}$ ); tricuspid regurgitation grade and gradient remained unchanged. In the 2004 cohort right ventricular reverse remodeling was observed (right ventricular long axis, $71 \pm 6$ vs $69 \pm 9 \mathrm{~mm}$; right ventricular short axis, $29 \pm 5$ vs $27 \pm 5 \mathrm{~mm} ; P<.0001$ ); tricuspid regurgitation diminished ( $1.6 \pm 1.0$ vs $0.9 \pm 0.6, P<.0001)$, and transtricuspid gradient decreased ( $28 \pm 13 \mathrm{vs} 23 \pm 15 \mathrm{~mm}$ $\mathrm{Hg}, P=.021$ ). Subanalysis of the 2002 cohort showed that in 23 patients without grade 3 or 4 tricuspid regurgitation but baseline tricuspid annular dilatation, the degree of tricuspid regurgitation was worse at the 2-year follow-up. Moreover, this caused right ventricular dilatation. Subanalysis of the 2004 cohort demonstrated reverse right ventricular remodeling and decreased tricuspid regurgitation in 43 patients with preoperative tricuspid annular dilatation who underwent tricuspid annuloplasty.
\end{abstract}

Conclusions: Concomitant tricuspid annuloplasty during mitral valve repair should be considered in patients with tricuspid annular dilatation despite the absence of important tricuspid regurgitation at baseline because this improves echocardiographic outcome. (J Thorac Cardiovasc Surg 2011;141:1431-9)

In patients scheduled for mitral valve surgery, tricuspid regurgitation (TR) is not uncommon. A decrease in TR has been noted after mitral valve surgery because of reduced right ventricular pressure or volume overload. Still, progression of TR without left-sided valvular dysfunction or de novo TR can be observed during follow-up. ${ }^{1}$ In particular, TR after successful left-sided valve surgery has been reported in up to $74 \%$ of patients at long-term follow-up and is associated with poor outcome. ${ }^{1-3}$ Concomitant tricuspid

\footnotetext{
From the Departments of Cardiology and Thoracic Surgery, ${ }^{\mathrm{b}}$ Leiden University Medical Center, Leiden, The Netherlands.

Disclosures: Dr Bax received grants from Biotronik, Medtronic, Boston Scientific Corporation, Bristol-Myers Squibb Medical Imaging, St Jude Medical, GE Healthcare, and Edwards Lifesciences. Dr Dion discloses that he is on the speakers' bureau of Edward Lifesciences. The other authors have nothing to disclose.

Received for publication Jan 30, 2010; revisions received April 3, 2010; accepted for publication May 30, 2010; available ahead of print Sept 10, 2010.

Address for reprints: Nico R. Van de Veire, MD, PhD, Department of Cardiology, Leiden University Medical Center, PO Box 9600, 2300 RC Leiden, The Netherlands (E-mail: N.R.L.van_de_Veire@lumc.nl).

$0022-5223 / \$ 36.00$

Copyright (C) 2011 by The American Association for Thoracic Surgery

doi:10.1016/j.jtcvs.2010.05.050
}

valve repair with an annuloplasty ring in patients with moderate or severe TR undergoing left-sided valve surgery has been shown to improve (event-free) survival. ${ }^{4}$ Various authors have suggested that at the time of mitral valve surgery, tricuspid annuloplasty should be considered when tricuspid annular dilatation is present. ${ }^{2,5-8}$ Recently published European Society of Cardiology guidelines recommend tricuspid valve repair in case of left-sided valve surgery when there is severe TR but also when there is annular dilatation $(\geq 40 \mathrm{~mm})$ of the tricuspid valve. ${ }^{9}$ The American College of Cardiology and American Heart Association guidelines state that tricuspid annuloplasty might be considered in patients undergoing mitral valve surgery when there is tricuspid annular dilatation. ${ }^{10}$ The absence of TR and right ventricular reverse remodeling after restrictive tricuspid annuloplasty would support this approach. However, echocardiographic studies addressing these specific questions are scarce. Accordingly, we evaluated echocardiographic outcomes at a 2-year follow-up in patients with organic or functional mitral regurgitation who underwent mitral valve repair in 2002 and 2004, respectively. 


\section{Abbreviation and Acronym \\ $\mathrm{TR}=$ tricuspid regurgitation}

\section{MATERIALS AND METHODS \\ Study Population}

The patient population consisted of 182 patients who underwent mitral valve repair in 2002 or 2004 and completed a 2-year follow-up echocardiographic analysis.

The 2002 cohort included 80 consecutive patients with severe mitral valve regurgitation who underwent mitral valve repair and completed the 2-year echocardiographic follow-up. The mechanism of mitral regurgitation was organic in $71 \%$ of cases and functional in $29 \%$ of cases. Coronary artery bypass graft surgery was performed simultaneously in $24 \%$ of patients.

The 2004 cohort included 102 consecutive patients with severe mitral regurgitation who underwent mitral valve repair and completed the 2year echocardiographic follow-up. The mechanism of mitral regurgitation was organic in $50 \%$ of cases and functional in $50 \%$ of cases. Coronary artery bypass graft surgery was performed simultaneously in $24 \%$ of patients. Our institution's ethics committee approved conducting this retrospective study and waived the need for individual consent.

\section{Clinical Assessment}

Every patient underwent clinical assessment by a physician who was blinded to the echocardiographic data. New York Heart Association class and Canadian Cardiac Society score were used at baseline and at the 2year follow-up.

\section{Echocardiography}

The clinical echocardiographic evaluation was as follows. A transthoracic echocardiogram was performed within 5 days before the operation and at the 2-year follow-up. Patients were imaged in the left lateral decubitus position by using a commercially available system (Vingmed System Five or Vivid Seven; GE, Horten, Norway). Images were obtained with a $3.5-\mathrm{MHz}$ transducer at a depth of $16 \mathrm{~cm}$ in the parasternal and apical views (standard long-axis, 2-chamber, and 4-chamber images). The left atrial diameter and left ventricular dimensions (end-systolic and end-diastolic diameters) were determined from parasternal M-mode acquisitions. Color flow was applied in the apical views to evaluate mitral regurgitation and TR. The severity of mitral regurgitation was characterized as mild ( 1 ; jet area/left atrial area, $<10 \%)$, moderate $(2$; jet area/left atrial area, $10 \%-20 \%)$, moderately severe $(3$; jet area/left atrial area, $20 \%-45 \%)$, and severe $(4$; jet area/left atrial area, $>45 \%){ }^{11}$ The severity of TR was characterized as trivial ( 1 ; jet area/right atrial area, $<10 \%$ ), mild $(2$; jet area/right atrial area, $10 \%-20 \%)$, moderate $(3$; jet area/right atrial area, $20 \%-33 \%$ ), and severe (4; jet area/right atrial area, $\geq 33 \%)^{12}$ The trans-TR gradient was quantified (modified Bernoulli equation) by using continuous-wave Doppler scanning. From the apical 4-chamber view, the ultrasound beam was oriented to obtain the maximum dimensions of the right ventricular chamber. Measurements were made of the right ventricular long and short axis, as well as the tricuspid valve annulus. ${ }^{13}$ The tricuspid annulus was measured in the transthoracic apical 4chamber view in late diastole at the time of maximal tricuspid opening (Figure 1).

\section{Surgical Procedure}

The procedures were performed with the use of normothermic cardiopulmonary bypass with intermittent antegrade warm blood cardioplegia for myocardial protection. After median sternotomy, patients with an

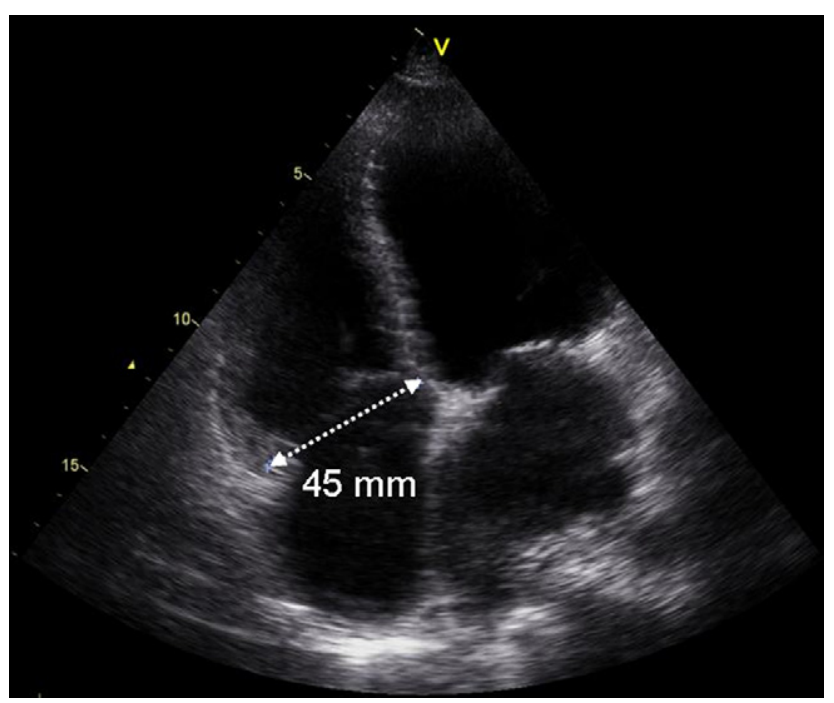

FIGURE 1. The tricuspid annular diameter is measured from the preoperative, transthoracic, apical 4-chamber view in late diastole, as recommended by Foale and associates. ${ }^{13}$ In this example the tricuspid annulus (45 $\mathrm{mm})$ is dilated.

indication for revascularization underwent coronary artery bypass grafting; for patients younger than 70 years, a strategy of total arterial revascularization was used. Next, the right atrium was opened, and after a vertical transseptal approach, mitral valve repair was performed after thorough intraoperative valve analysis. In the case of organic disease, mitral valve reconstruction was conducted by using standard Carpentier techniques. ${ }^{14}$ Mitral annuloplasty ring size (Carpentier-Edwards Physioring; Edwards Lifesciences, Irvine, Calif) was determined by means of standard measurement of the height of the anterior leaflet. In the case of functional mitral regurgitation, stringent downsizing by 2 ring sizes was performed. In the 2002 cohort tricuspid annuloplasty was performed only when the preoperative echocardiogram demonstrated grade 3 or 4 TR. In the 2004 cohort tricuspid annuloplasty was performed when the preoperative echocardiogram demonstrated grade 3 or 4 TR or in any case when tricuspid annulus enlargement $(\geq 40 \mathrm{~mm})$ had been observed, as proposed recently. ${ }^{15}$ A Carpentier-Edwards Classic annuloplasty ring (18\%) or Edwards $\mathrm{MC}^{3}$ annuloplasty ring $(82 \%$; both manufactured by Edwards Lifesciences) was used. The ring size was determined by means of standard measurement of the surface of the anterior leaflet in organic cases. In functional cases a restrictive ( 1 size under) annuloplasty was performed. After weaning from cardiopulmonary bypass, the result of the valve reconstructions was checked with transesophageal echocardiographic analysis.

\section{Statistical Analysis}

Continuous data were expressed as means \pm standard deviations and compared by using the Student $t$ test for paired and unpaired data when appropriate. Comparison of categorical data was performed with $\chi^{2}$ analysis. Comparisons within each cohort of patients were performed by using the Student $t$ test or nonparametric tests for paired and unpaired data, as appropriate. In addition, each cohort was divided into 3 subgroups: patients with TR grade 3 or 4 , patients without TR grade 3 or 4 but with tricuspid annular dilatation of $40 \mathrm{~mm}$ or greater, and patients without TR grade 3 or 4 or tricuspid annular dilatation of $40 \mathrm{~mm}$ or greater. Comparisons among the 3 different subgroups were performed with 1-way analysis of variance or the Kruskal-Wallis test, as appropriate. All statistical analyses were performed with SPSS software (version 15.0; SPSS, Inc, Chicago, Ill). 


\section{RESULTS}

\section{Baseline Characteristics}

Baseline clinical characteristics of the 2002 and 2004 cohorts are presented in Table 1. There is a male predominance in both cohorts, and $34 \%$ of the patients have a history of myocardial infarction. Patients from the 2004 cohort were older than patients from the 2002 cohort. All patients were receiving optimized medical treatment. Risk factors, medical history, and functional class were similar. Preoperative echocardiographic characteristics are presented in Table 2. Left ventricular dimensions and function, as well as severity of mitral regurgitation, were comparable between the 2 cohorts. TR was similar between both cohorts, as were right ventricular dimensions.

\section{Surgical Details}

All patients underwent successful mitral valve repair (ie, no residual mitral regurgitation and a coaptation length $\geq 8 \mathrm{~mm}$ ). The mitral mean ring size used was $30 \pm 4 \mathrm{~mm}$ in the 2002 cohort compared with $28 \pm 3 \mathrm{~mm}$ in the 2004 cohort. Tricuspid annuloplasty was performed in $13(16 \%)$ patients of the 2002 cohort and in $64(63 \%)$ patients of the 2004 cohort. The tricuspid mean ring size used was $32 \pm 3$ $\mathrm{mm}$ in the 2002 cohort compared with $29 \pm 2 \mathrm{~mm}$ in the 2004 cohort. Coronary artery bypass grafting was performed in 19 patients of the 2002 cohort and 35 patients of the 2004 cohort. Cardiopulmonary bypass time and clamp time were comparable between the groups: $173 \pm 52$ versus $162 \pm 52$ minutes and $119 \pm 44$ versus $101 \pm 46$ minutes, respectively.

\section{Two-Year Follow-up}

Clinical and echocardiographic 2-year follow-ups of the entire 2002 and 2004 cohorts are presented in Tables 3 and 4. A significant difference in New York Heart Association functional class was observed at follow-up. In both groups the expected reduction of mitral regurgitation was noted

TABLE 1. Baseline clinical characteristics

\begin{tabular}{lccc}
\hline & $\begin{array}{c}\mathbf{2 0 0 2} \text { cohort } \\
(\mathbf{n}=\mathbf{8 0})\end{array}$ & $\begin{array}{c}\mathbf{2 0 0 4} \text { cohort } \\
(\mathbf{n = 1 0 2})\end{array}$ & $\boldsymbol{P}$ value \\
\hline Men/women & $44(55 \%) / 36(45 \%)$ & $62(61 \%) / 40(39 \%)$ & .50 \\
Mean age $\pm \mathrm{SD}, \mathrm{y}$ & $60 \pm 15$ & $66 \pm 12$ & .010 \\
Arterial & $10(13 \%)$ & $20(20 \%)$ & .091 \\
$\quad$ hypertension & & & \\
Diabetes & $6(8 \%)$ & $10(10 \%)$ & .67 \\
Severe COPD & $6(8 \%)$ & $8(8 \%)$ & .99 \\
Previous stroke & $3(4 \%)$ & $3(3 \%)$ & .84 \\
Previous infarction & $19(24 \%)$ & $31(30 \%)$ & .19 \\
Previous CABG & $19(24 \%)$ & $35(34 \%)$ & .093 \\
NYHA class & $2.6 \pm 0.8$ & $2.6 \pm 0.8$ & .49 \\
CCS class & $1.3 \pm 0.6$ & $1.3 \pm 0.8$ & .61 \\
\hline
\end{tabular}

$S D$, Standard deviation; $C O P D$, chronic obstructive pulmonary disease; $C A B G$, coronary artery bypass grafting; NYHA, New York Heart Association; CCS, Canadian Cardiac Society.
TABLE 2. Baseline echocardiographic characteristics

\begin{tabular}{lccc}
\hline & $\begin{array}{c}\text { 2002 cohort } \\
(\mathbf{n}=\mathbf{8 0})\end{array}$ & $\begin{array}{c}\text { 2004 cohort } \\
(\mathbf{n}=\mathbf{1 0 2})\end{array}$ & $\boldsymbol{P}$ value \\
\hline Left atrial diameter (mm) & $50 \pm 10$ & $47 \pm 7$ & .092 \\
LV end-diastolic diameter (mm) & $61 \pm 9$ & $59 \pm 8$ & .25 \\
LV end-systolic diameter (mm) & $42 \pm 11$ & $42 \pm 11$ & .93 \\
Fractional shortening (\%) & $31 \pm 12$ & $29 \pm 13$ & .84 \\
Mitral regurgitation grade & $3.4 \pm 0.7$ & $3.2 \pm 0.7$ & .20 \\
RV long axis (mm) & $69 \pm 7$ & $72 \pm 8$ & .15 \\
RV short axis (mm) & $29 \pm 7$ & $29 \pm 5$ & .98 \\
Tricuspid valve annulus (mm) & $38 \pm 7$ & $39 \pm 5$ & .34 \\
Tricuspid regurgitation grade & $1.6 \pm 1.0$ & $1.6 \pm 1.0$ & .85 \\
Transtricuspid gradient (mmHg) & $25 \pm 10$ & $28 \pm 13$ & .11 \\
\hline
\end{tabular}

after surgical intervention. This observation was accompanied by a matched reduction in left atrial and left ventricular dimensions, indicating reverse remodeling after surgical intervention. In the 2002 cohort, right ventricular dimensions, TR grade, and gradient remained unchanged after surgical intervention. In the 2004 cohort, the right ventricular dimensions decreased after surgical intervention accompanied by a reduction in TR and transtricuspid gradient.

In summary, echocardiographic outcome at the 2-year follow-up did not improve in the 2002 cohort patients who did not undergo tricuspid annuloplasty in case of tricuspid annular dilatation. In contrast, 2004 cohort patients who underwent combined mitral valve repair and tricuspid annuloplasty in case of severe TR or tricuspid annular dilatation demonstrated reverse right ventricular remodeling and reduction of TR.

\section{Subgroup Analysis of the 2002 Cohort}

At the 2-year follow-up, the expected reduction of mitral regurgitation and left atrial and ventricular reverse remodeling was also observed in the different subgroups of the 2002 cohort (Table 5). In 2002, only patients with a grade 3 or 4 TR underwent tricuspid valve annuloplasty. In these 13 patients TR was absent or mild at the 2-year follow-up, and there was also a significant decrease of the transtricuspid

TABLE 3. Two-year follow-up: Entire 2002 cohort

\begin{tabular}{lccc}
\hline & Baseline & Follow-up & $\boldsymbol{P}$ value \\
\hline New York Heart Association class & $2.6 \pm 0.8$ & $1.4 \pm 0.6$ & $<.0001$ \\
Canadian Cardiac Society class & $1.3 \pm 0.6$ & $1.0 \pm 0.2$ & $<.001$ \\
LA diameter (mm) & $50 \pm 10$ & $43 \pm 8$ & $<.0001$ \\
LV end-diastolic diameter (mm) & $61 \pm 9$ & $52 \pm 10$ & $<.0001$ \\
LV end-systolic diameter (mm) & $42 \pm 11$ & $35 \pm 11$ & $<.0001$ \\
Mitral regurgitation grade & $3.4 \pm 0.7$ & $0.7 \pm 0.8$ & $<.0001$ \\
RV long axis (mm) & $69 \pm 7$ & $70 \pm 8$ & .301 \\
RV short axis (mm) & $29 \pm 7$ & $30 \pm 7$ & .080 \\
Tricuspid regurgitation grade & $1.6 \pm 1.0$ & $1.3 \pm 1.0$ & .211 \\
Transtricuspid gradient (mm Hg) & $25 \pm 10$ & $23 \pm 9$ & .091 \\
\hline
\end{tabular}

$L A$, Left atrial; $L V$, left ventricular; $R V$, right ventricular. 
TABLE 4. Two-year follow-up: Entire 2004 cohort

\begin{tabular}{llcl}
\hline & Baseline & Follow-up & $\boldsymbol{P}$ value \\
\hline New York Heart Association class & $2.6 \pm 0.8$ & $1.8 \pm 0.8$ & $<.0001$ \\
Canadian Cardiac Society class & $1.3 \pm 0.8$ & $1.1 \pm 0.2$ & $<.001$ \\
LA diameter (mm) & $48 \pm 7$ & $44 \pm 7$ & $<.0001$ \\
LV end-diastolic diameter (mm) & $59 \pm 8$ & $53 \pm 9$ & $<.0001$ \\
LV end-systolic diameter (mm) & $42 \pm 11$ & $38 \pm 12$ & $<.0001$ \\
Mitral regurgitation grade & $3.3 \pm 0.5$ & $0.8 \pm 0.8$ & $<.0001$ \\
RV long axis (mm) & $71 \pm 6$ & $69 \pm 9$ & .001 \\
RV short axis (mm) & $29 \pm 5$ & $27 \pm 5$ & $<.0001$ \\
Tricuspid regurgitation grade & $1.6 \pm 1.0$ & $0.9 \pm 0.6$ & $<.0001$ \\
Transtricuspid gradient (mm Hg) & $28 \pm 13$ & $23 \pm 15$ & .021 \\
\hline
\end{tabular}

$L A$, Left atrial; $L V$, left ventricular; $R V$, right ventricular.

gradient (Figure 2). Moreover, these patients showed reverse right ventricular remodeling, as expressed by a significant decrease of the right ventricular long- and short-axis diameters (Figure 3). In the 44 patients without significant TR and without tricuspid annular dilatation at baseline, the degree of TR and right ventricular dimensions remained unchanged (Figures 2 and 3). However, in patients with a dilated tricuspid annulus $(\geq 40 \mathrm{~mm})$, the degree of TR at the 2-year follow-up was worse, and the transtricuspid gradient had increased significantly in these 23 patients (Figure 2). Moreover, this was associated with right ventricular dilatation (Figure 3). Note that these patients did not undergo tricuspid annuloplasty.

\section{Subgroup Analysis of the 2004 Cohort}

At the 2-year follow-up, significant reduction of mitral regurgitation and left atrial and ventricular reverse remodeling was observed in all subgroups of the 2004 cohort (Table 6). In the 2004 cohort, patients underwent annuloplasty of the mitral and tricuspid valves if grade 3 or 4 TR was present at baseline or if the tricuspid annulus was dilated $(\geq 40$ $\mathrm{mm}$ ), irrespective of the degree of TR preoperatively. Both in the 21 patients with severe baseline TR and in the 43 patients with tricuspid annular dilatation who underwent tricuspid annuloplasty, TR and transtricuspid gradient decreased significantly at the 2-year follow-up (Figure 4). Moreover, these patients showed a significant decrease of right ventricular dimensions, indicating reverse right ventricular remodeling (Figure 5). Patients without important TR and without tricuspid annular dilatation at baseline did not undergo tricuspid annuloplasty. The degree of TR regurgitation and right ventricular dimensions remained unchanged in these 38 patients (Figures 4 and 5).

\section{DISCUSSION}

The main novel findings of the current study are as follows. In patients with tricuspid annular dilatation undergoing mitral valve reconstruction without concomitant tricuspid surgery, right ventricular dimensions increased, and TR was aggravated at the 2-year follow-up. In contrast, right ventricular reverse remodeling and absence of significant TR were observed at the 2-year follow-up in patients with tricuspid annular dilatation who underwent simultaneous tricuspid annuloplasty during mitral valve surgery.

\section{Incidence and Prognostic Implications of Tricuspid Valve Regurgitation After Mitral Valve Surgery}

Tricuspid valve regurgitation occurs mainly from annular and right ventricular dilatation, which is often secondary to left-sided valvular causes, right ventricular volume and pressure overload, and dilatation of cardiac chambers. ${ }^{8}$ It was thought for a long time that this functional TR would decrease or disappear over time after surgical correction of mitral regurgitation. ${ }^{16}$ There is, however, increasing evidence that TR does not always regress after successful surgical treatment of mitral regurgitation. Often, progression of TR is observed after mitral valve surgery or appears de novo during postoperative follow-up. ${ }^{17-19}$ Kwak and colleagues ${ }^{1}$ investigated the incidence of significant TR in 335 patients after left-sided valve surgery (mean follow-up, 11 years;

TABLE 5. Echocardiographic left-sided follow-up of 2002 cohort by subgroup

\begin{tabular}{|c|c|c|c|}
\hline & $\begin{array}{c}\text { Tricuspid regurgitation } \\
\geq \mathbf{3} \text { (TVP), } \mathbf{n}=13\end{array}$ & $\begin{array}{l}\text { Tricuspid regurgitation }<3 \text { and } \\
\text { tricuspid annulus } \geq 40 \mathrm{~mm}, \mathrm{n}=\mathbf{2 3}\end{array}$ & $\begin{array}{l}\text { Tricuspid regurgitation }<3 \text { and } \\
\text { tricuspid annulus }<40 \mathrm{~mm}, \mathrm{n}=44\end{array}$ \\
\hline \multicolumn{4}{|c|}{ Left atrial diameter $(\mathrm{mm})$} \\
\hline Baseline & $50 \pm 13$ & $52 \pm 9$ & $48 \pm 9^{*}$ \\
\hline Follow-up & $41 \pm 10(P=.001)$ & $46 \pm 9(P=.004)$ & $42 \pm 8^{*}(P<.0001)$ \\
\hline \multicolumn{4}{|c|}{ Left ventricular end-diastolic diameter (mm) } \\
\hline Baseline & $59 \pm 11$ & $63 \pm 10$ & $59 \pm 8^{*}$ \\
\hline Follow-up & $51 \pm 10(P=.016)$ & $56 \pm 10(P<.0001)$ & $51 \pm 9^{*}(P<.01)$ \\
\hline \multicolumn{4}{|c|}{ Left ventricular end-systolic diameter (mm) } \\
\hline Baseline & $45 \pm 10$ & $42 \pm 13$ & $40 \pm 11^{*}$ \\
\hline Follow-up & $36 \pm 10(P=.005)$ & $38 \pm 13(P=.037)$ & $33 \pm 11 *(P<.0001)$ \\
\hline \multicolumn{4}{|c|}{ Mitral regurgitation grade } \\
\hline Baseline & $3.3 \pm 0.6$ & $3.4 \pm 0.5$ & $3.5 \pm 0.7^{*}$ \\
\hline Follow-up & $0.9 \pm 0.8(P<.0001)$ & $0.9 \pm 0.8(P<0.0001)$ & $0.5 \pm 0.9 *(P<.0001)$ \\
\hline
\end{tabular}

$P$ values refer to baseline versus follow-up comparison. TVP, Tricuspid valve annuloplasty. *Not significant for comparison among the 3 groups (analysis of variance). 


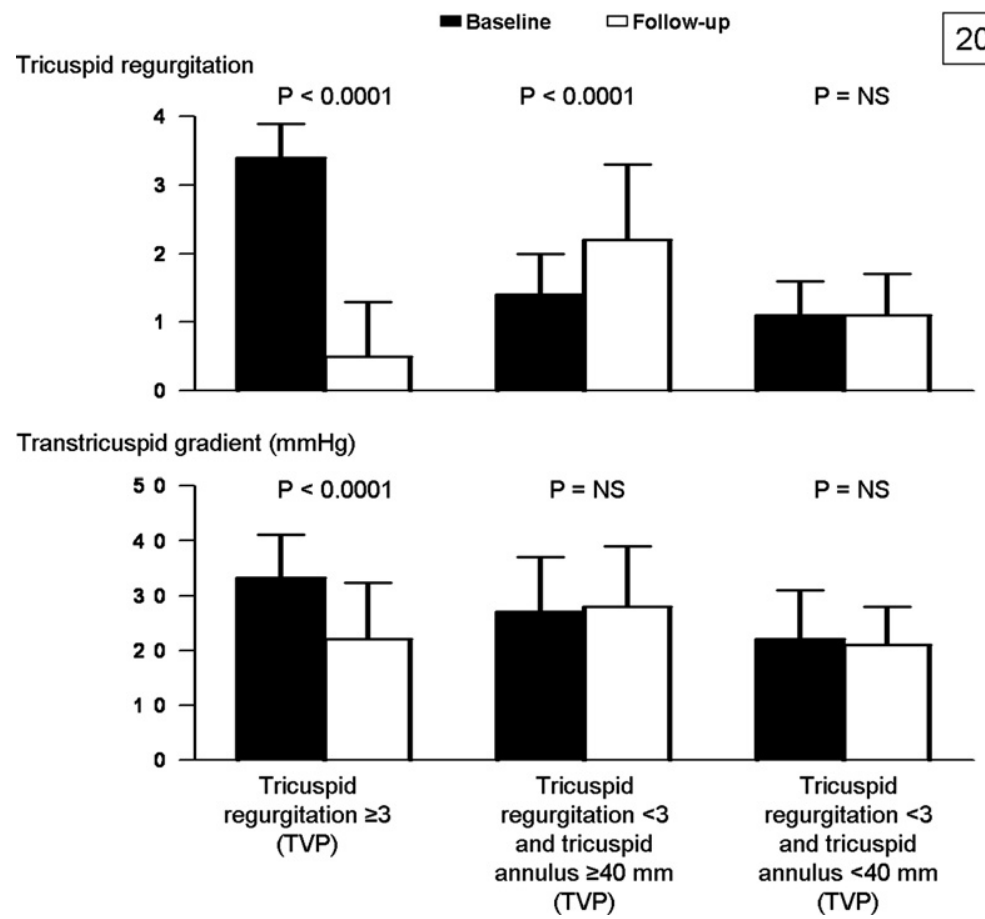

FIGURE 2. Echocardiographic evaluation of tricuspid regurgitation and gradient at baseline and at the 2-year follow-up in the 2002 cohort according to subgroups. NS, Not significant; TVP, tricuspid valve annuloplasty.

$52 \%$ mitral valve surgery, $22 \%$ aortic valve surgery, and $26 \%$ combined aortic/mitral valve surgery). The estimated incidence of TR was $27 \%$ and was related to poor out- come. ${ }^{1}$ Matsunaga and Duran ${ }^{6}$ more specifically studied 70 patients with ischemic cardiomyopathy and secondary mitral regurgitation who underwent coronary artery bypass

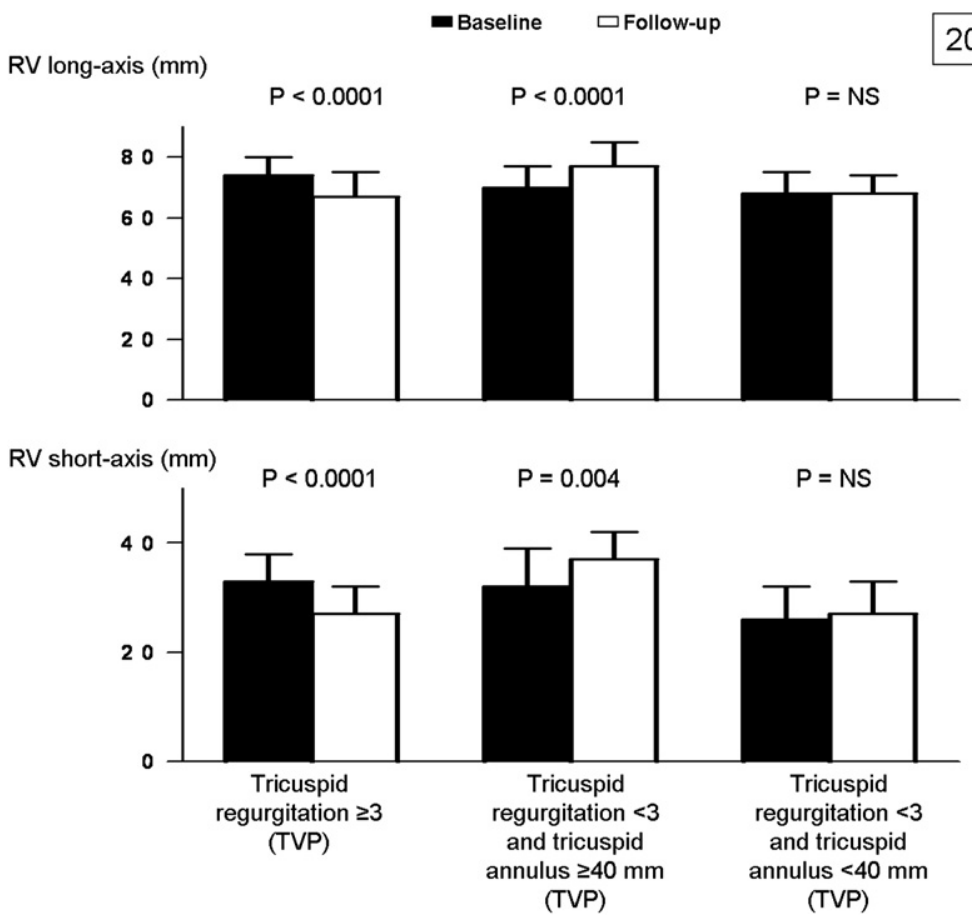

FIGURE 3. Echocardiographic evaluation of right ventricular $(R V)$ dimensions at baseline and at the 2-year follow-up in the 2002 cohort according to subgroups. NS, Not significant; TVP, tricuspid valve annuloplasty. 
TABLE 6. Echocardiographic left-sided follow-up of 2004 cohort by subgroup

\begin{tabular}{|c|c|c|c|}
\hline & $\begin{aligned} & \text { Tricuspid } \\
& \text { regurgitation } \\
& \geq \mathbf{3}(\mathrm{TVP}), \mathbf{n}=\mathbf{2 1} \\
&\end{aligned}$ & $\begin{array}{c}\text { Tricuspid regurgitation }<3 \text { and } \\
\text { tricuspid annulus } \geq 40 \mathrm{~mm} \\
(\mathrm{TVP}), \mathrm{n}=\mathbf{4 3}\end{array}$ & $\begin{array}{c}\text { Tricuspid regurgitation }<3 \text { and } \\
\text { tricuspid annulus }<40 \mathrm{~mm} \\
(\mathrm{TVP}), \mathrm{n}=\mathbf{3 8}\end{array}$ \\
\hline \multicolumn{4}{|c|}{ Left atrial diameter $(\mathrm{mm})$} \\
\hline Baseline & $47 \pm 7$ & $47 \pm 8$ & $49 \pm 5^{*}$ \\
\hline Follow-up & $44 \pm 6(P=.025)$ & $44 \pm 8(P=.008)$ & $44 \pm 7 *(P<.001)$ \\
\hline \multicolumn{4}{|c|}{ Left ventricular end-diastolic diameter (mm) } \\
\hline Baseline & $60 \pm 8$ & $60 \pm 8$ & $57 \pm 9^{*}$ \\
\hline Follow-up & $54 \pm 10(P=.007)$ & $54 \pm 9(P<.001)$ & $53 \pm 9 *(P=.004)$ \\
\hline \multicolumn{4}{|c|}{ Left ventricular end-systolic diameter (mm) } \\
\hline Baseline & $44 \pm 12$ & $42 \pm 12$ & $40 \pm 10^{*}$ \\
\hline Follow-up & $39 \pm 13(P=.010)$ & $39 \pm 12(P=.019)$ & $36 \pm 12 *(P=.014)$ \\
\hline \multicolumn{4}{|c|}{ Mitral regurgitation grade } \\
\hline Baseline & $3.3 \pm 0.8$ & $3.3 \pm 0.6$ & $3.2 \pm 0.5^{*}$ \\
\hline Follow-up & $0.6 \pm 0.6(P<.0001)$ & $0.7 \pm 0.8(P<.0001)$ & $1.0 \pm 0.9 *(P<.0001)$ \\
\hline
\end{tabular}

$P$ values refer to baseline versus follow-up comparison. TVP, Tricuspid valve annuloplasty. *Not significant for comparison among the 3 groups (analysis of variance).

graft surgery and mitral valve repair with a flexible Duran ring. The incidence of significant TR was $25 \%$ within the 1-year follow-up and increased to $53 \%$ between the 1- and 3-year follow-ups; at late follow-up ( $>3$ years), the incidence was $74 \%{ }^{6}$

\section{Combining Mitral Valve Surgery and Tricuspid Valve Repair}

These observations have encouraged surgeons to perform tricuspid valve repair at the time of mitral valve repair. In the 1970s, Carpentier and coworkers ${ }^{20}$ performed tricuspid valve surgery when medical therapy failed. In the 1980s, Duran and associates ${ }^{21}$ suggested that functional TR could only be ignored in cases of predictable and significant reduction in pulmonary resistance and that organic disease always required repair. Nowadays, most surgeons agree that moderate-to-severe TR should be repaired, and it has been shown that tricuspid annuloplasty is associated with better symptomatic results and improved survival. ${ }^{22}$

Carpentier and coworkers ${ }^{23}$ were the first to recognize the importance of tricuspid annular dilatation as an indication for tricuspid valve repair. Their method of assessing

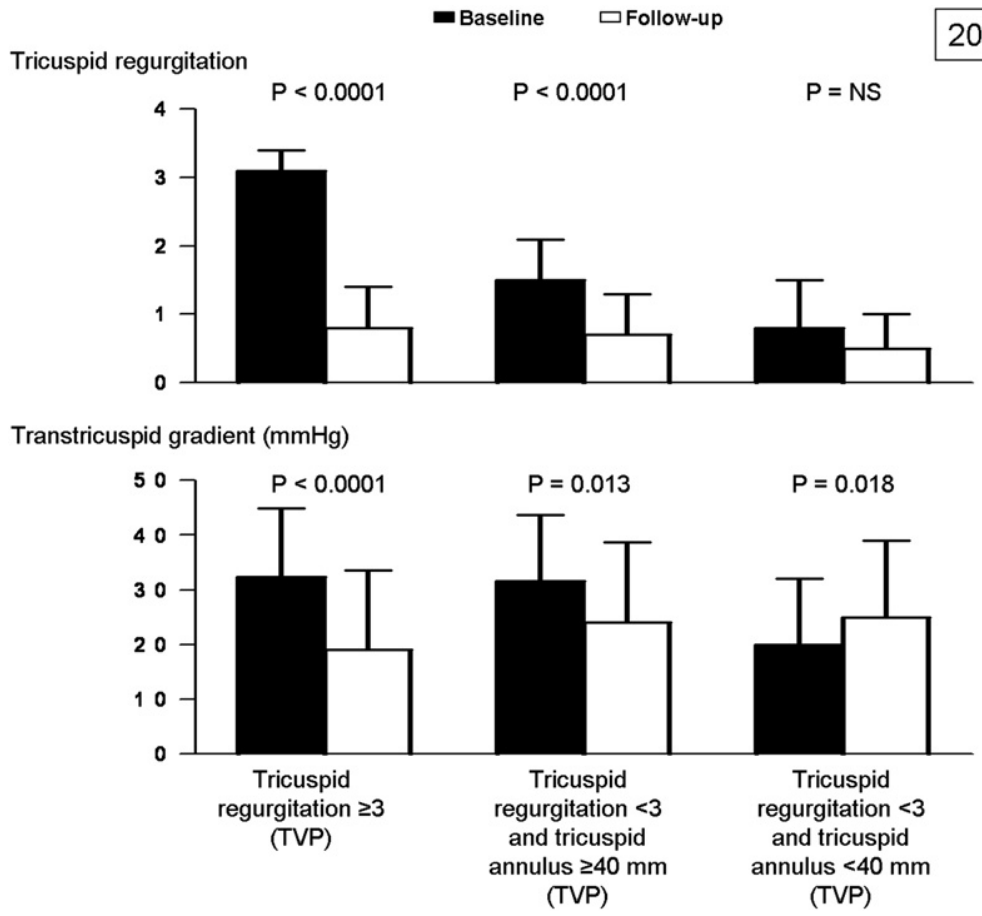

FIGURE 4. Echocardiographic evaluation of tricuspid regurgitation and gradient at baseline and the 2-year follow-up in the 2004 cohort according to subgroups. NS, Not significant; TVP, tricuspid valve annuloplasty. 

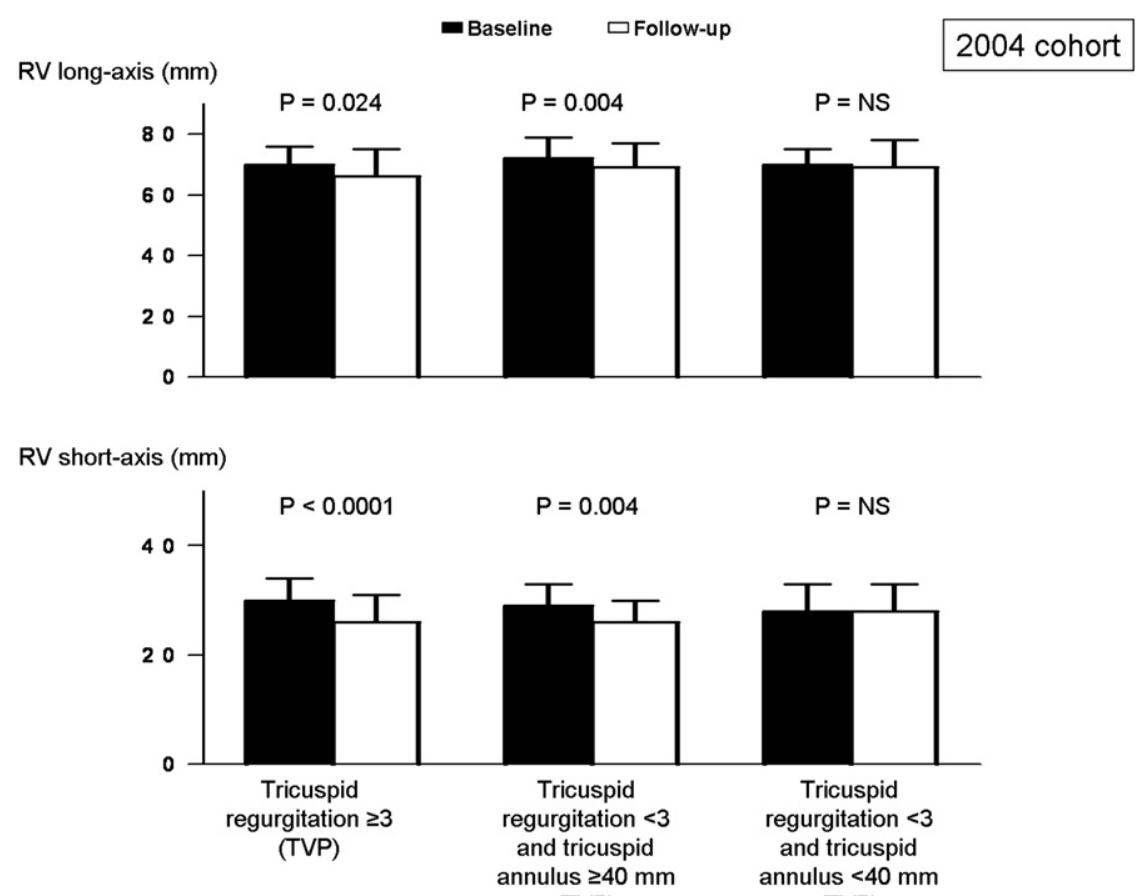

(TVP)

(TVP)

FIGURE 5. Echocardiographic evaluation of right ventricular $(R V)$ dimensions at baseline and the 2-year follow-up in the 2004 cohort according to subgroups. NS, Not significant; TVP, tricuspid valve annuloplasty.

annular dilatation was surgical exploration of the valve and the ability of the annulus to admit 3 finger breadths of the surgeon's hand, in which case it would be repaired. ${ }^{22}$ Dreyfus and colleagues ${ }^{5}$ suggested that in addition to tricuspid dilatation, 3 important factors determine whether TR will occur: preload, afterload, and right ventricular function. Isolated mitral valve surgery decreases the afterload without correcting tricuspid annular dilatation, and it does not affect preload or right ventricular function. ${ }^{5}$ Tricuspid annular dilatation is an ongoing disease process that will with time lead to severe TR.

\section{Surgical Methods to Treat or Prevent TR}

There are 2 principal surgical methods to treat or prevent TR: the ring annuloplasty, as introduced by Carpentier and associates ${ }^{23}$ and the suture annuloplasty method, mostly performed as described by De Vega and coworkers. ${ }^{24}$ Although either method can be applied for secondary TR, recent longterm studies suggest that ring annuloplasty repairs are more robust. ${ }^{2,25,26}$ Tang and associates ${ }^{2}$ compared the long-term results of tricuspid valve repair with or without an annuloplasty ring. The authors included 702 patients $(74 \%$ functional TR), of whom 493 underwent a De Vega procedure and 209 had annuloplasty. Concomitant procedures consisted of mitral valve surgery in $80 \%$, aortic valve surgery in $33 \%$, and coronary bypass surgery in $14 \%$. Tricuspid valve repair without a ring was associated with TR recurrence over time. The patients who received a ring had significantly improved long-term and event-free survival.

\section{Results of Tricuspid Valve Surgery in Patients With a Dilated Tricuspid Annulus}

The relevance of performing tricuspid annuloplasty in patients with a dilated tricuspid valve annulus has been demonstrated in several series. Tager and associates ${ }^{27}$ evaluated 144 patients undergoing mitral valve surgery. Tricuspid annuloplasty was performed in 49 patients, and the criteria used to indicate this procedure were the presence of moderate or severe TR or a tricuspid annular diameter, as assessed with echocardiographic analysis if $30 \mathrm{~mm}$ or greater. Interestingly, those patients who did not show significant TR but had a tricuspid annular diameter of 30 $\mathrm{mm}$ or greater and in whom tricuspid annuloplasty was not performed showed an increased prevalence of significant TR at follow-up $(13 \%)$. Sugimoto and colleagues ${ }^{28}$ demonstrated higher right ventricular volume and pressure, which are indicative of right-sided heart failure, in patients undergoing left-sided valvular surgery with a tricuspid annulus of $40 \mathrm{~mm}$ or greater compared with patients without tricuspid annular dilatation. In patients with a dilated tricuspid annulus undergoing combined mitral and tricuspid surgery, TR decreased. ${ }^{28}$ In 2005, Dreyfus and colleagues ${ }^{5}$ reported on 311 patients who underwent mitral valve repair. The authors defined a dilated annulus as a diameter of greater than $70 \mathrm{~mm}$ measured peroperatively from the anteroseptal commissure to the anteroposterior commissure with a sterile ruler. Tricuspid annuloplasty was performed only if the tricuspid annular diameter was greater than twice the normal size $(>70 \mathrm{~mm})$, regardless of the grade 
of TR. In patients who did not undergo annuloplasty, TR increased by more than 2 grades in $48 \%$ of patients compared with only $2 \%$ of patients who underwent tricuspid annuloplasty.

The present study focused on patients with severe organic or functional mitral regurgitation scheduled for mitral valve repair. The surgical approach for the mitral regurgitation was consistent for all patients. In 2002, only patients with TR grade 3 or 4 underwent tricuspid annuloplasty. In these patients TR improved, and right ventricular dimensions decreased. Based on the work of Sugimoto and colleagues ${ }^{28}$ tricuspid annular dilatation was defined as an annulus exceeding $40 \mathrm{~mm}$ on echocardiographic analysis. The patients from the 2002 cohort without preoperative TR grade 3 or 4 but with a dilated annulus had a higher degree of TR at the 2-year follow-up. These findings are well in line with recent data in comparable patients. ${ }^{29}$ De Bonis and associates ${ }^{29}$ assessed the evolution of functional TR in 95 patients who underwent surgical repair of functional mitral regurgitation with or without concomitant tricuspid annuloplasty. Tricuspid annuloplasty was only performed in 13 patients with preoperative TR grade 3 or 4 . At the 6-month echocardiographic follow-up, functional TR was moderate in $31 \%$, moderate to severe in $10 \%$, and severe in $2 \%$. The mechanism underlying tricuspid dilatation was annular dilatation. Moreover, in the present study right ventricular dimensions increased in the patients with tricuspid annular dilatation who did not undergo tricuspid repair. These data support the observation of Sugimoto and colleagues ${ }^{28}$ that tricuspid annular dilatation is associated with evidence of right-sided heart failure. In our clinic, from 2004 on, tricuspid annuloplasty was not only applied in patients undergoing mitral valve repair with TR grade 3 or 4 but also in patients with tricuspid annular dilatation, irrespective of the degree of regurgitation. Reverse right ventricular remodeling and a reduction of TR severity were observed, supporting a more aggressive approach in these patients.

\section{CONCLUSIONS}

Patients with tricuspid annular dilatation $(\geq 40 \mathrm{~mm})$ undergoing mitral valve repair without concomitant tricuspid valve annuloplasty have poor echocardiographic outcomes. They exhibit right ventricular dilatation and significantly increased TR at the 2-year follow-up. A more aggressive surgical approach favoring tricuspid annuloplasty in case of tricuspid annular dilatation improves echocardiographic outcomes significantly. These patients demonstrate the absence of hemodynamically relevant TR and right ventricular reverse remodeling at the 2-year follow-up. Combined mitral repair and tricuspid annuloplasty should be considered in patients with tricuspid annular dilatation despite the absence of important TR at baseline.

\section{References}

1. Kwak J-J, Kim Y-J, Kim M-K, Kim H-K, Park J-S, Kim K-H, et al. Development of tricuspid regurgitation late after left-sided valve surgery: a single center experience with long-term echocardiographic examinations. Am Heart J. 2008;155:732-7.

2. Tang GHL, David TE, Singh SK, Maganti MD, Armstrong S, Borger MA. Tricuspid valve repair with an annuloplasty ring results in improved long-term outcomes. Circulation. 2006;114(suppl I):I577-81

3. Song H, Chung CH, Choo SJ, Song MG, Song J-M, Kang D-H, et al. Factors associated with development of late significant tricuspid regurgitation after successful left-sided valve surgery. Heart. 2009;95:931-6.

4. Colombo T, Russo C, Ciliberto GR, Lanfranconi M, Bruschi G, Agati S, et al. Tricuspid regurgitation secondary to mitral valve disease: tricuspid annulus function as guide to tricuspid valve repair. Cardiovasc Surg. 2001;9:369-77.

5. Dreyfus GD, Corbi PJ, Chan J, Bahrami T. Secondary tricuspid regurgitation or dilatation: which should be the criteria for surgical repair? Ann Thorac Surg. 2005;79:127-32.

6. Matsunaga A, Duran CMG. Progression of tricuspid regurgitation after repaired functional ischemic mitral regurgitation. Circulation. 2005;112(suppl I):I453-7.

7. Shiran A, Sagie A. Tricuspid regurgitation in mitral valve disease. Incidence, prognostic implications, mechanisms, and management. J Am Coll Cardiol. 2009;53:401-8

8. Rogers JH, Bolling SF. The tricuspid valve: current perspective and evolving management of tricuspid regurgitation. Circulation. 2009;119:2718-25.

9. Vahanian A, Baumgartner H, Bax J, Butchart E, Dion R, Filippatos G, et al. Guidelines on the management of valvular heart disease. The task force on the management of valvular heart disease of the European Society of Cardiology. Eur Heart J. 2007;28:230-68.

10. Bonow RO, Carabello BA, Chatterjee K, de Leon AC Jr, Faxon DP, Freed MD, et al. 2008 Focused update incorporated into the ACC/AHA 2006 guidelines for the management of patients with valvular heart disease. J Am Coll Cardiol. 2008; 52:e1-142.

11. Thomas JD. How leaky is that mitral valve? Simplified Doppler methods to measure regurgitant orifice area. Circulation. 1997;95:548-50.

12. Chopra HK, Nanda NC, Fan P, Kapur KK, Goyal R, Daruwalla D, et al. Can twodimensional echocardiography and Doppler color flow mapping identify the need for tricuspid valve repair? J Am Coll Cardiol. 1989;14:1275-7.

13. Foale R, Nihoyannopoulos P, McKenna W, Klienebenne A, Nadazin A, Rowland E, et al. Echocardiographic measurement of the normal adult right ventricle. Br Heart J. 1986;56:33-44.

14. Filsoufi F, Carpentier A. Principles of reconstructive surgery in degenerative mitral valve disease. Semin Thorac Cardiovasc Surg. 2007;19:103-10.

15. Dreyfus GD, Chan KMJ. Functional tricuspid regurgitation: a more complex entity than it appears. Heart. 2009;95:868-9.

16. Braunwald NS, Ross J, Morrow AG. Conservative management of tricuspid regurgitation in patients undergoing mitral valve replacement. Circulation. 1967;35(suppl I):I63-9.

17. Groves PH, Ikram S, Ingold U, Hall RJ. Tricuspid regurgitation following mitral valve replacement: an echocardiographic study. J Heart Valve Dis. 1993;2:273-8.

18. Porter A, Shapira Y, Wurzel M, Sulkes J, Vaturi M, Adler Y, et al. Tricuspid regurgitation late after mitral valve replacement: clinical and echocardiographic evaluation. J Heart Valve Dis. 1999;8:57-62.

19. Izumi C, Iga K, Konishi T. Progression of isolated tricuspid regurgitation late after mitral valve surgery for rheumatic mitral valve disease. J Heart Valve Dis. 2002;11:353-6.

20. Carpentier A, Deloche A, Hanania G, Forman J, Sellier P, Piwnica A, et al. Surgical management of acquired tricuspid valve disease. J Thorac Cardiovasc Surg. 1974;67:53-65.

21. Duran CMG, Pomar JL, Colman T, Figueroa A, Revuelta JM, Ubago JL. Is tricuspid valve repair necessary? J Thorac Cardiovasc Surg. 1980;80:849-60.

22. Anyanwu AC, Chikwe J, Adams DH. Tricuspid valve repair for treatment and prevention of secondary tricuspid regurgitation in patients undergoing mitral valve surgery. Curr Cardiol Rep. 2008;10:110-7.

23. Carpentier A, Deloche A, Dauptain J, Soyer R, Blondeau P, Piwnica A, et al. A new reconstructive operation for correction of mitral and tricuspid insufficiency. J Thorac Cardiovasc Surg. 1971;61:1-13.

24. De Vega NG, De Rabago G, Castillon L, Moreno T, Azpitarte J. A new tricuspid repair. Short-term clinical results in 23 cases. J Cardiovasc Surg (Torino). 1973. Spec No:384-6.

25. McCarthy PM, Bhudia SK, Rajeswaran J, Hoercher KJ, Lytle BW, Cosgrove DM, et al. Tricuspid valve repair: durability and risk factors for failure. J Thorac Cardiovasc Surg. 2004;127:674-85. 
26. Roshanali F, Saidi B, Mandegar MH, Yousefnia MA, Alaeddini F. Echocardiographic approach to the decision-making process for tricuspid valve repair. J Thorac Cardiovasc Surg. 2010;139:1483-7.

27. Tager R, Skudicky D, Mueller U, Essop R, Hammond G, Sareli P. Long-term follow-up of rheumatic patients undergoing left-sided valve replacement with tricuspid annuloplasty - validity of preoperative echocardiographic criteria in the decision to perform tricuspid annuloplasty. Am J Cardiol. 1998;81:1013-6.
28. Sugimoto T, Okada M, Ozaki N, Hatakeyama T, Kawari T. Long-term evaluation of treatment for functional tricuspid regurgitation with regurgitant volume: characteristic differences based on primary cardiac lesion. J Thorac Cardiovasc Surg. 1999;117:463-71.

29. De Bonis M, Lapenna E, Sorrentino F, La Canna G, Grimaldi A, Maisano F, et al Evolution of tricuspid regurgitation after mitral valve repair for functional mitral regurgitation in dilated cardiomyopathy. Eur J Cardiothorac Surg. 2008;33:600-6.

Access to The Journal of Thoracic and Cardiovascular Surgery Online is reserved for print subscribers!

Full-text access to The Journal of Thoracic and Cardiovascular Surgery Online is available for all print subscribers. To activate your individual online subscription, please visit The Journal of Thoracic and Cardiovascular Surgery Online, point your browser to http://www.mosby.com/itcvs, follow the prompts to activate your online access, and follow the instructions. To activate your account, you will need your subscriber account number, which you can find on your mailing label (note: the number of digits in your subscriber account number varies from 6 to 10). See the example below in which the subscriber account number has been circled:

\section{Sample mailing label}

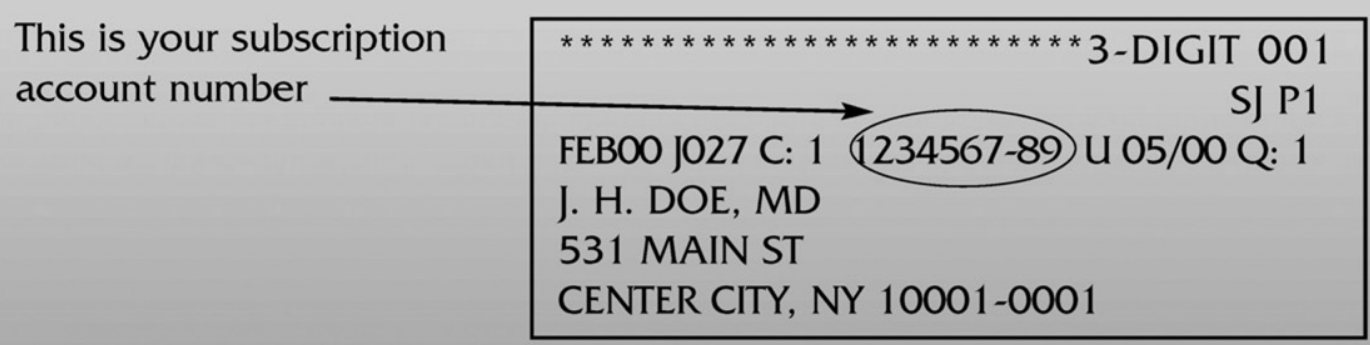

Personal subscriptions to The Journal of Thoracic and Cardiovascular Surgery Online are for individual use only and may not be transferred. Use of The Journal of Thoracic and Cardiovascular Surgery Online is subject to agreement to the terms and conditions as indicated online. 